\title{
Materials shape the Olympic Winter Games
}

$\mathrm{A}^{\mathrm{s}}$ I write this article, we are 22 days away from the start of the 2018 Olympic Winter Games, ${ }^{1}$ which will be held in Pyeongchang, South Korea, from February 9 to 25. By the time you read this, the Games will be over. Consequently, being a connoisseur of the Olympics, I take this opportunity to make some bold predictions. First, records will be broken in many events. Second, some events will inspire significant controversy surrounding the judging. Third, viewers worldwide will be riveted to their television sets during much of the Games. Fourth, new technologies inspired by materials research will contribute to the performances of many athletes.

The first Olympic Winter Games were held in Chamonix, France, in $1924^{2}$ and subsequently took place every four years from 1924 through 1992. After that, they were shifted by two years to be offset from the Olympic Summer Games. The history of winter sports however predates the Winter Games. Skiing dates back at least 5000 years, although some suggest that Chinese paintings created 10,000 years ago depict skiing. ${ }^{3}$ Skiing was an efficient method of travel across snow. Early skis were made of bone or wood, often with an animal skin attached.

The earliest history of ice skating is identified to be around 3000 years ago. ${ }^{4}$ Skating was also an efficient method of travel on ice and snow. The earliest ice skates were flattened bones or other materials that were strapped to the feet to allow people to glide more easily on ice. Steel blades with sharp edges for cutting into the ice did not appear until around 1200-1300 AD.

In time, these purely practical skills on snow and ice were socialized for winter enjoyment. In recent decades, modern facilities have proliferated into areas that do not have a cool enough climate to support outdoor winter sports. Many otherwise balmy cities (such as Los Angeles) have professional ice hockey teams and year-round access to ice skating rinks. Huge indoor skiing facilities have been built in places around the world, including Egypt and the United Arab Emirates. ${ }^{5}$ These ice rinks and indoor ski facilities are possible through the development of more efficient air conditioning and refrigeration systems, as well as the ability to produce snow and properly conditioned ice. As those of you familiar with ice skating know, machines (commonly Zambonis) used to clean and resurface ice in rinks have improved significantly over the years.

There is a long history of advances in technologies and materials used to make skis. ${ }^{6}$ Although a ski appears to be a rather simple piece of lightweight synthetic material, making skis involves intertwined issues of physics, engineering, and materials science. ${ }^{7}$ Skis need to be lightweight so they can be maneuvered easily across surfaces, and yet strong enough to survive encounters with ice and rocks and the stresses associated with sudden stops or high-speed turns. Skis must also be waterproof. They are constructed with two kinds of camber, or bend, in order to more evenly balance the weight of the skier and to allow the skier to turn while in motion.?

There are at least four types of skis: downhill, slalom (a ski race down a winding course marked by flags or poles), giant slalom, and cross-country. Each are available in different lengths and construction. Core materials include wood, polyurethane foams, and aluminum honeycombs. Modern ski construction is complex and can include wood, metal, plastics, fiberglass, carbon, neoprene, or ceramics. ${ }^{8}$ Skis have multiple layers that are bonded using resin. The edges of the skis are usually made of steel. Hydrocarbon and fluorocarbon waxes are used to control the friction between the ski and the snow/ice surfaces. Some of the waxes incorporate graphite to reduce the buildup of electrical charge that can increase friction. ${ }^{8}$

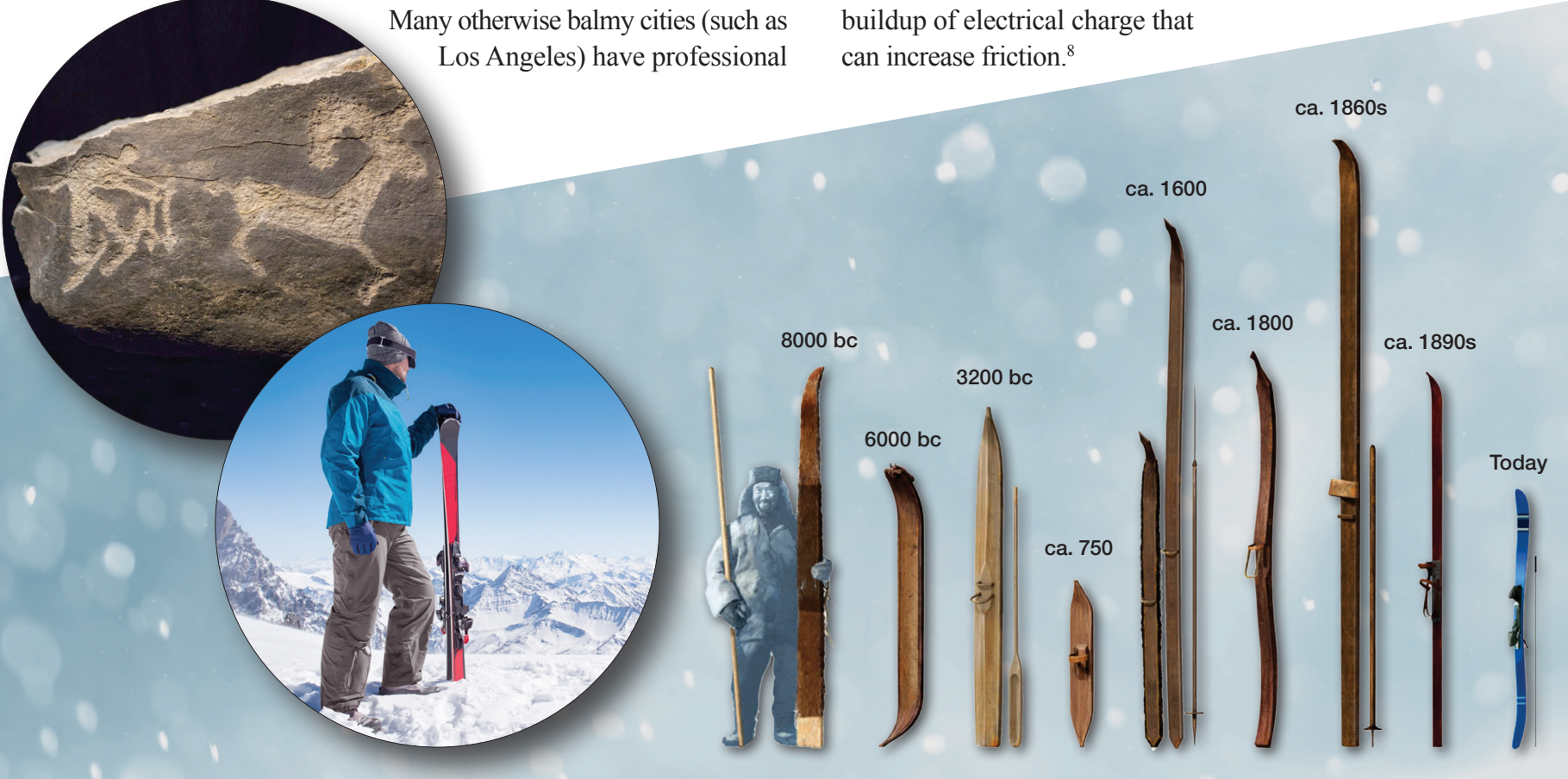


The short discussion here does not amply describe the complexity of modern skis and the techniques and materials used to build them. I haven't touched on the bindings, ski boots, poles, helmets, and other ski gear. Skis and equipment used in competitions must withstand the forces and torques encountered during trying conditions, such as the Alpine skiing events (downhill, slalom, and giant slalom). Those forces and torques are enormous and are becoming more strenuous on the equipment as speeds become faster and athletes set new records.

There have been many advances in the materials used to make ice skates. There are three basic types: those for ice hockey, figure skating, and speed skating. Ice skates are made from "... leather, nylon, plastic, steel, and various other synthetic materials." 9 The blades are typically made of tempered steel (sometimes including titanium) and coated with chrome. The geometry of the blades depends on their intended application. Many of the features of skates used in competition are based upon considerations of safety involving the potential of skates to cut the skater or another competitor. The blades used in competitions must also be strong enough to withstand the forces and torques applied during use. ${ }^{9}$

Although most of you are not Olympic-quality athletes, I am sure that some of you have excellent skills at winter sports. You spend significant amounts of money on gear, lift tickets at ski slopes, rink access, and travel. You ski the double black diamond slopes and moguls and fly downhill. Or you effortlessly and gracefully execute triple axels on ice skates. Ice hockey is second nature to you.

That's not me. I am a total klutz. I've never been on ice skates. I've been skiing several times. At best, it would be fair to state that I have rudimentary skills. I spend more time down than up. I tremendously admire the level of skills that I see in winter sporting events. The closest that I come these days to any kind of winter sport is the Short Ice Sprint (uncontrolled glide) across streets and sidewalks in Boston as I join my colleagues in a bar or restaurant outside the Hynes Convention Center at the MRS Fall Meetings. Or the Triple

Slip, Slide, and

Stumble followed by the uncontrolled Briefcase Hurl on the slippery sidewalks during winter weather. Or the Rhythmic Umbrella Dance on Ice with the umbrella twirled up to keep the sleet off my head, then twirled to the side to keep me from getting splashed by the slush of a pothole that traffic has directed my way.

Over the years, the proliferation of facilities and equipment for winter sports has encouraged the expansion of participants by enabling people from various countries to become more competitive. In 1988, Michael Edwards (aka Eddie the Eagle) represented Great Britain in the ski jump at the Calgary Olympics. ${ }^{10}$ He was the first person to represent Great Britain in this sport in almost six decades. He finished last in both of his events, but his courage and determination in the face of significant opposition inspired many. In 1992, Annelise Coberger of New Zealand became the first person from the Southern Hemisphere to medal in a Winter Olympics by taking the silver medal in slalom at the Albertville Olympic Games. ${ }^{11}$ In that same event at Albertville, Blanca Fernández Ochoa won the bronze medal and became the first Spanish woman to win an Olympic Medal. Finally, who could forget the Jamaican bobsled team ${ }^{12}$ who first appeared at the 1988 Calgary Games and have appeared in five other Olympic Winter Games since, most recently at the Sochi Games in 2014.

One of my favorite sports in the Winter Games is the chaotic venture known as short track speed skating. ${ }^{13}$ It combines the features of speed skating with those of a roller derby. ${ }^{14}$ The races and their outcomes are very contentious. The inclusion of events such as short track speed skating and the half-pipe ${ }^{15}$ for skiers and snowboarders has certainly made the Games more exciting, but they undoubtedly place significant stress on skating, skiing, and snowboard materials.

I look forward to the Games in South Korea with the competition, exposure to people of different cultures, and their personal stories. If many records are broken in highly successful events, you can attribute much of this to the development of excellent facilities and new sports gear, which are connected explicitly to materials research.

Steve Moss

\section{References}

1. www.olympic.org/pyeongchang-2018.

2. Wikipedia, Winter Olympic Games, https:// en.wikipedia.org/wiki/Winter_Olympic_ Games.

3. Wikipedia, Skiing, https://en.wikipedia.org/wiki/ Skiing.

4. Wikipedia, Ice skating, https://en.wikipedia.org/ wiki/lce_skating\#Rising_popularity_and_first_ clubs.

5. Wikipedia, Indoor skiing, https://en.wikipedia. org/wiki/Indoor_skiing.

6. International Skiing History Association, A short history of skis, www.skiinghistory.org/history/ short-history-skis-0.

7. Advameg, How products are made: Ski, www. madehow.com/Nolume-2/Ski.html.

8. Mechanics of Sport, Ski construction, www. mechanicsofsport.com/skiing/equipment/skis/ ski_construction.html.
9. Advameg, How products are made: Ice skates www.madehow.comNolume-2/lce-Skates.html.

10. Wikipedia, Eddie "The Eagle" Edwards, https: //en.wikipedia.org/wiki/Eddie_\%22The_Eagle\% 22_Edwards.

11. International Olympic Committee, Coberger strikes winter games first for southern hemisphere, www.olympic.org/news/coberger-strikes-winter-games-first-for-southern-hemisphere.

12. Wikipedia, Jamaica national bobsleigh team, https://en.wikipedia.org/wiki/Jamaica_national_ bobsleigh_team.

13. International Olympic Committee, Short track speed skating, www.olympic.org/short-track-speed-skating.

14. Wikipedia, Roller derby, https://en.wikipedia.org/ wiki/Roller_derby.

15. Wikipedia, Half-pipe skiing, https:/en.wikipedia. org/wiki/Half-pipe_skiing. 